\title{
Relação entre preço da carne bovina e do animal comercializado em Cuiabá, MT
}

Relationship between the prices of cattle beef and animal negotiated in Cuiabá, MT

\author{
Tatiane Beloni ${ }^{*} ;$ Marcell Patachi Alonso²
}

\author{
1 Universidade Federal de São Carlos - Docente no Departamento de Biotecnologia e Produção Vegetal e \\ Animal - Rod. Anhanguera Km 174 - Zona Rural - CEP 13.604-900 - Araras (SP), Brasil \\ ${ }^{2}$ Escola Superior de Agricultura Luiz de Queiroz da Universidade de São Paulo - Doutorando em Ciência \\ Animal e Pastagens - Departamento de Zootecnia - Av. Pádua Dias, 11 - CEP 13.418-900 - Piracicaba \\ (SP), Brasil
}

\section{Resumo}

Os ciclos de produção da cadeia da carne bovina são influenciados por vários fatores que afetam os preços pagos pelo frigorífico ao produtor e os preços da carne no varejo. $O$ intuito deste estudo foi verificar o comportamento e determinar a relação entre o preço por kg dos principais cortes da carne bovina e a arroba comercializada na região de Cuiabá, no Estado de Mato Grosso. As variáveis estudadas foram o preço da arroba do boi gordo e da vaca gorda na região de Cuiabá, e dos cortes: Contrafilé, Picanha, Coxão Mole, Acém, Músculo e Cupim, no Estado de Mato Grosso. Realizou-se uma análise descritiva determinando-se os coeficientes de correlação e análise de regressão, por meio de dados disponibilizados em boletins semanais do Instituto Mato-Grossense de Economia Agropecuária, de novembro de 2013 a outubro de 2016. Foram obtidos altos coeficientes de correlação significativos entre os preços dos cortes com o preço da arroba do boi e da vaca. As equações de regressão geradas apresentaram altos coeficientes de determinação. O comportamento dos preços dos cortes apresenta-se variável ao longo do tempo, pois os preços são afetados pelo preço da arroba do boi gordo e da vaca gorda. Estes por sua vez, tem seus preços influenciados principalmente pela oferta de matrizes para o abate, pelo clima e por fatores econômicos. Os preços dos cortes da carne bovina estudados estão, forte e positivamente, relacionados aos preços da arroba do boi gordo e da vaca gorda, permitindo sua estimativa a partir de modelos empíricos.

Palavras-chave: boi gordo, bovinocultura de corte, cortes comerciais, frigorífico

\begin{abstract}
Several factors influence the production cycle of beef cattle chain affecting the prices paid by slaughterhouse to the producer and the prices of meat in retail. The purpose of this study was to verify the behavior and determine the relationship between the price per $\mathrm{kg}$ of the main meat cuts and the arroba (14.69 kg) commercialized in the region of Cuiabá in the State of Mato Grosso. The evaluated variables were arroba price of Steers/Bullock and Cow in Cuiabá region, and the cuts: Sirloin Steak, Top Sirloin CAP, Topside, Chuck, Shank and Hump Steak, in the State of Mato Grosso. A descriptive analysis was carried out by determining correlation coefficients and regression analysis, using data available in weekly bulletins from the Instituto Mato-Grossense de Economia Agropecuária from November 2013 to October 2016. High correlation coefficients were obtained between cuts prices and the arroba price of Steers/Bullock and of Cow. The regression equations generated showed high coefficients of determination. The behavior of cut prices was variable over time, as it is affected by arroba price of Steers/Bullock and Cow. These, in turn, have their prices influenced mainly by the supply of matrices for slaughter, by the climate and by economic factors. The prices of the beef cuts studied are strongly and positively related to the arroba prices of Steers/Bullock and Cow, allowing their estimation from empirical models. Keywords: Beef cattle, commercial cuts, slaughterhouse, steers/bullock
\end{abstract}

\footnotetext{
* Autor correspondente: <tbeloni@usp.br> Enviado: 21 fev. 2017 Aprovado: 24 abr. 2017
} 


\section{Introdução}

O rebanho bovino brasileiro atingiu o recorde de 215,2 milhões de animais em 2015, com um aumento de 1,3\% sobre 2014 (IBGE, 2016). O Centro-Oeste apresentou um acréscimo de $2,1 \%$ e continua a ser a região que concentra a maior criação, com $33,8 \%$ da participação nacional, sendo o Estado de Mato Grosso o maior criador de gado, com 13,6\% do total nacional (IBGE, 2016). No Brasil, a carne bovina é um dos itens mais importantes da dieta alimentar (IBGE, 2012), onde mais de $80 \%$ da produção nacional de carne bovina é consumida pelo mercado interno (ABIEC, 2016). Estes fatores ressaltam a importância de identificar as particularidades que determinam o padrão da cadeia produtiva deste produto.

A produção de carne bovina é uma atividade econômica que, por um lado, envolve as fases biológicas de produção (cria, recria e engorda) e por outro, a utilização de fatores de produção (terra, benfeitorias, instalações, pastagens, medicamentos e outros insumos, administração, mão-de-obra e outros serviços) que, convertidos em valores e comparados aos preços vigentes, determinam a economicidade do sistema em uso (Arruda, 2002). Para a obtenção do melhor resultado financeiro, é imprescindível o conhecimento dos custos incorridos e possíveis em outras oportunidades, no entanto, o crescimento da atividade não foi acompanhado pelo desenvolvimento e implementação de técnicas de gestão, sendo observado resistência dos pecuaristas e dificuldade de mensuração dos custos (Raupp e Fuganti, 2014).

$\mathrm{Na}$ cadeia produtiva da carne, o preço e o volume de compra são determinados pelos frigoríficos, uma vez que estes apresentam o seu custo marginal, ou o valor da arroba, igual a sua receita marginal. Diante disso, os frigoríficos são capazes de decidir qual volume demandarão e qual preço pagarão (Pindyck e Rubinfeld, 1994). Por sua vez, para que os produtores determinem individualmente as quantidades de produção em que maximizam seus lucros, devem potencializar o acréscimo de volume, e administrar seus custos marginais. Na visão de Viana et al. (2009) a sazonalidade, o clima e o mercado são alguns fatores que podem interferir na oferta total, tornando instável a produção e, por conseguinte, a receita ao longo dos anos.

Em relação à margem do varejo esta é a que mais participa do preço pago pelo consumidor, cerca de 64\% (IMEA, 2009a). O setor é desarticulado e desorganizado nas bases da produção, da indústria e do varejo (Potter, 2000), e os supermercados, açougues e boutiques de carnes, são os responsáveis pela distribuição da carne ao consumidor. De uma forma geral, são eles que estabelecem as regras na cadeia da 
carne bovina e têm um papel muito significativo na definição dos preços, pela informação direta de sensibilidade do consumidor (IMEA, 2009a).

Neste cenário, o produtor está entre setores de mercado altamente especializados e incapaz de formular os preços finais de seu produto (Montoya e Parre, 2000). E além disso, o produtor é altamente dependente do poder aquisitivo do mercado consumidor para o qual sua produção se destina (Arbage, 2000).

Diante do exposto, o objetivo deste estudo foi verificar o comportamento e determinar a relação entre o preço por $\mathrm{kg}$ dos principais cortes de carne bovina e o preço por arroba comercializado de diferentes categorias de animais na região de Cuiabá no Estado de Mato Grosso.

\section{Material e Métodos}

A pesquisa utilizou dados disponibilizados em boletins semanais do Instituto Mato-Grossense de Economia Agropecuária [IMEA], sendo analisados publicações dos últimos 36 meses, de novembro de 2013 a outubro de 2016 (IMEA, 2009b). As variáveis estudadas foram o preço da arroba (14,69 $\mathrm{kg}$ de peso de carcaça) do boi gordo e da vaca gorda praticados na região de Cuiabá e dos principais cortes de carne bovina em kg comercializados no Estado de Mato Grosso (Filé Mignon, Contrafilé, Picanha, Alcatra, Coxão Mole, Coxão Duro, Patinho, Acém, Músculo, Costela, Fraldinha, Lagarto, Maminha, Cupim e Paleta).

Os preços da arroba do boi gordo e da vaca gorda são disponibilizados diariamente, sendo 20 publicações mensais (dias úteis). Os valores correspondentes aos preços do $\mathrm{kg}$ dos cortes de carne são divulgados mensalmente. Portanto, com o intuito de padronizar os valores da arroba do boi gordo e da vaca gorda, trabalhou-se com suas respectivas médias aritméticas mensais.

As variáveis em estudo foram submetidas ao teste de normalidade de ShapiroWilks e, no caso da não significância $(p<0,05)$ - distribuição não normal dos dados - as variáveis foram retiradas da avaliação. Diante disso, as análises foram realizadas utilizando variáveis com distribuição normal. Foi observado que apenas seis cortes (Contrafilé, Picanha, Coxão Mole, Acém, Músculo e Cupim), apresentaram distribuição normal dos dados (Tabela 1). 
Tabela 1. Resultado do teste de normalidade de Shapiro-Wilks para as variáveis em estudo

\begin{tabular}{lccc}
\hline \multicolumn{1}{c}{ Variáveis } & Unidade & Distribuição dos dados & p-valor \\
\hline Preço da arroba do boi & arroba & não normal & $<0,01$ \\
Preço da arroba da vaca & arroba & não normal & $<0,01$ \\
\hline Filé Mignon & $\mathrm{kg}$ & não normal & $<0,01$ \\
Contrafilé & $\mathrm{kg}$ & normal & 0,120 \\
Picanha & $\mathrm{kg}$ & normal & 0,107 \\
Alcatra & $\mathrm{kg}$ & não normal & 0,020 \\
Coxão Mole & $\mathrm{kg}$ & normal & 0,096 \\
Coxão Duro & $\mathrm{kg}$ & não normal & 0,011 \\
Patinho & $\mathrm{kg}$ & não normal & 0,019 \\
Acém & $\mathrm{kg}$ & normal & 0,053 \\
Músculo & $\mathrm{kg}$ & normal & 0,285 \\
Costela & $\mathrm{kg}$ & não normal & 0,029 \\
Fraldinha & $\mathrm{kg}$ & não normal & $<0,01$ \\
Lagarto & $\mathrm{kg}$ & não normal & $<0,01$ \\
Maminha & $\mathrm{kg}$ & não normal & 0,036 \\
Cupim & $\mathrm{kg}$ & normal & 0,198 \\
Paleta & $\mathrm{kg}$ & não normal & $<0,01$ \\
\hline
\end{tabular}

Fonte: Dados originais da pesquisa

Desta forma, estes cortes foram escolhidos para uma análise mais criteriosa, ou seja, seu preço de comercialização por kg em relação a variação do preço da arroba do boi gordo e da vaca gorda. Realizou-se a análise de estatística descritiva dos dados, o coeficiente correlação linear de Pearson e a determinação de modelos de regressão linear simples sendo utilizado o critério de informação de Akaike. As análises foram realizadas com o auxílio do Programa Estatístico Past versão 3.14.

\section{Resultados e Discussão}

No Brasil gasta-se muito com alimentação. Em Cuiabá cerca de 53,21\% do salário mínimo líquido é comprometido com a aquisição de alimentos (DIEESE, 2016). E, segundo De Paula et al. (2011), a carne é apontada como o produto que mais sobrecarrega a cesta de alimentos. Por meio da análise dos valores máximos e mínimos pode-se observar a ampla variação existente quanto aos valores de comercialização dos cortes analisados. Contrafilé, Acém e Músculo apresentaram preços por kg que se repetiram ao longo dos 36 meses (Tabela 2 ). 
Tabela 2. Estatística descritiva (Valor mínimo, Valor máximo, Erro Padrão da Média e Moda [EPM]) dos preços da arroba do boi gordo [boi] e da vaca gorda [vaca] e dos cortes de carne bovina em kg (Contrafilé, Picanha, Coxão Mole, Acém, Músculo e Cupim)

\begin{tabular}{lccccc}
\hline \multicolumn{1}{c}{ Descrição } & $\begin{array}{c}\text { Valor } \\
\text { mínimo }\end{array}$ & Valor máximo & Média & EPM & Moda \\
\hline Boi & ----------- & & \\
Vaca & 96,11 & 138,13 & 124,93 & 2,06 & 0,00 \\
Contrafilé & 89,31 & 129,75 & 117,37 & 2,03 & 0,00 \\
Picanha & 19,10 & 28,65 & 24,12 & 0,43 & 25,86 \\
Coxão Mole & 26,50 & 40,60 & 34,28 & 0,58 & 0,00 \\
Acém & 16,69 & 23,56 & 19,96 & 0,32 & 0,00 \\
Músculo & 9,83 & 15,87 & 12,69 & 0,28 & 12,09 \\
Cupim & 11,05 & 15,86 & 13,38 & 0,23 & 13,84 \\
\hline
\end{tabular}

Fonte: Resultados originais da pesquisa

Na literatura sobre preços pecuários, foi enfatizado que tanto os preços quanto a produção são influenciados por condições climáticas sazonais, fatores econômicos e cíclicos (Lazzarini Neto e Nehmi Filho, 1997; Sachs e Margarido, 2007; Wedekin, 2009; Pimentel, 2011). Os preços pecuários são consequência do equilíbrio entre oferta e demanda. A curva da oferta pecuária bovina de corte considera fatores como a produção, as carnes alternativas, ciclo pecuário e, sobretudo, fatores ligados a exportações a renda per capita (Lazzarini Neto e Nehmi Filho, 1997).

O Produto Interno Bruto [PIB] também interferiu positivamente nos preços da carne bovina, pois um maior desenvolvimento econômico tende a pressionar a elevação dos preços. As exportações da mesma forma, como se trata de uma commodity exportável, quando o comércio com outros países apresenta um maior dinamismo o preço da arroba tende a se elevar (Abrita et al., 2014). Aliado a isto, o preço foi fortemente determinado pelas condições de oferta dos produtos, e no caso da carne identifica-se com o comportamento ao longo do tempo dos fatores que interferem em seu meio de produção.

A variação do preço iniciada no atacado foi ajustada por meio de defasagem distribuída no tempo pelos produtores e varejistas, ou seja, de forma assimétrica (Aguiar, 1993). A explicação estaria na estrutura concentrada do setor e na inelasticidade da demanda. Nesse sentido, Santana (1999) estimou que a elasticidadepreço da carne de boi foi de - 0,271, o que constituiu uma demanda inelástica. Outra causa, pode ser a diluição da valorização do preço da arroba nos diferentes cortes. Analisando por esta perspectiva, os cortes de Picanha, Contrafilé e Coxão Mole, 
apresentaram maior variação, e consequentemente valorizaram mais. Por lógica, o impacto do aumento destes cortes foi menor para o consumidor deste produto, do que para outro que adquire carnes de segunda.

Em relação às classificações por qualidade de cortes, carne de primeira e de segunda, as duas frentes são importantes para o seguimento da cadeia. Uma vez que a demanda interna por carne bovina pode ser separada em dois grupos: os consumidores de baixa renda, que se preocupam com a quantidade a ser consumida, tendo o preço como restrição e desta forma, optando pelas carnes com o preço mais acessível, e os consumidores de alto poder aquisitivo, que se preocupam com a qualidade do produto (Carvalho e Zen, 2010), e estão dispostos a pagar mais pela carne.

Para analisar esta sazonalidade da pecuária de corte, é necessário examinar a evolução do preço da carne bovina e da arroba, utilizou-se para este fim a análise de correlação, que indica a força e a direção do relacionamento linear entre dois fatores, trata-se, portanto, de uma medida da relação entre eles, embora correlação não implique causalidade (Moore, 2007). Observou-se que o preço do kg comercializado dos cortes de carne foi relacionado com o preço da arroba do boi gordo e da vaca de forma semelhante, de acordo com os altos coeficientes de correlação linear obtidos (Tabela 3). A associação entre as variáveis é forte, de acordo com a classificação de Dancey e Reidy (2006), uma vez que os valores encontrados estão entre 0,5 e 1.

Tabela 3. Coeficientes de correlação linear de Pearson do preço do $\mathrm{kg}$ dos cortes da carne bovina (Contrafilé, Picanha, Coxão Mole, Acém, Músculo e Cupim) em função do preço da arroba do Boi gordo [boi] e o da Vaca gorda [vaca]

\begin{tabular}{lcc}
\hline \multicolumn{1}{c}{ Variável } & Arroba do boi & Arroba da vaca \\
\hline Boi & 1 & $0,99^{\star *}$ \\
Vaca & $0,99^{\star *}$ & 1 \\
Contrafilé & $0,86^{* *}$ & $0,85^{\star *}$ \\
Picanha & $0,87^{\star *}$ & $0,89^{\star *}$ \\
Coxão Mole & $0,84^{\star *}$ & $0,85^{\star *}$ \\
Acém & $0,79^{* *}$ & $0,78^{\star *}$ \\
Músculo & $0,83^{* *}$ & $0,82^{\star *}$ \\
Cupim & $0,87^{* *}$ & $0,87^{\star *}$ \\
\hline
\end{tabular}

$*(p<0,01)$

Fonte: Resultados originais da pesquisa

É necessário explorar a natureza desta relação entre os atributos. A alta correlação entre a arroba do boi e da arroba da vaca, pode ser devido ao ciclo da pecuária, sendo este definido de acordo com quatro condicionantes: índices zootécnicos, clima, variáveis econômicas (oferta e demanda) e dupla aptidão das 
fêmeas. A matriz foi destinada a geração de bezerros, mas também se torna um bem de consumo quando destinada ao abate, ou seja, quando sua carne é o produto final. Entende-se, portanto, que o mercado do boi foi direcionado pela vaca, ou seja, o que o pecuarista faz com sua matriz foi que determina qual será o comportamento dos preços (Wedekin, 2009).

A sazonalidade, o clima e o mercado são alguns fatores que modificam a oferta total, tornando instável a produção, e, por conseguinte, a receita ao longo dos anos (Viana et al., 2009). Todos estes fatores podem provocar um excesso de oferta de animais para abate, e a queda preço como consequência, com o agravante de que estes produtos têm geralmente demanda inelástica (Santana, 1999), ampliando o efeito do excesso de oferta na redução de preços.

Individualmente os pecuaristas não têm o poder de influenciar seus preços, sendo essa decisão tomada pelos frigoríficos, isto não significa uma estabilização destes preços e, consequentemente, dos volumes produzidos. Como observado, as decisões dos frigoríficos se basearam na curva de oferta total à sua disposição, e esta curva sofre várias influências, e comumente chamada de ciclo da pecuária. $O$ mecanismo gerador dos ciclos funciona da seguinte maneira, quando a oferta de carne bovina está elevada em relação à demanda efetiva, os preços da carne no varejo e no atacado caem, sendo que a queda dos preços dos animais de reposição costuma ser mais intensa do que a ocorrida nos animais gordos (Martins et al., 2009). Com isso, o criador que produz bezerros tem perda de receita e é obrigado a vender suas matrizes para abate, o que agrava o desequilíbrio entre oferta e demanda de carne, acarretando novas rodadas de redução de preço (Boechat, 2014). Para Nehmi Filho (2007), as flutuações na produção de carne bovina estão ligadas à maior proporção de vacas nos frigoríficos. Quando o rebanho se estabiliza, o abate de fêmeas é limitado a matrizes descartadas no processo de produção, seja por velhice ou por infertilidade. No atual estágio da pecuária brasileira, o equilíbrio se dá quando o abate de fêmeas equivale a mais ou menos $45 \%$ do total (Boechat, 2014).

Por causa da estacionalidade climática, ocorrem dois períodos diferentes de oferta de carne bovina durante o ano. A safra, que corresponde aos meses de maior precipitação pluviométrica (setembro-outubro a abril-maio), e o período da entressafra, durante o período de inverno seco, quando a redução da precipitação pluviométrica e, menos favorável ao crescimento das forrageiras. Esta oscilação na capacidade de suporte das pastagens, em geral prolonga o período para terminação dos animais, adiando o tempo para o abate. Geralmente, os pecuaristas tentam contornar este 
problema, por meio do planejamento alimentar da fazenda, ou de forma mais prática e pontual diminuindo a lotação animal por hectare durante do período das chuvas (em torno de dois animais), o que garante excedente de forragem para consumo no inverno (Corrêa, 1988).

Em função da sazonalidade de oferta de animais aos frigoríficos, em grande parte relacionada a safra e entressafra, o preço pago pela arroba ao produtor apresentasse oscilante. Embora haja esta oscilação de preços pagos, em muitas situações, esta variação não foi refletida nos cortes vendidos na gôndola pelos mercados varejistas, ou seja, a participação do produtor no preço final da carne foi baixa.

Estes mercados varejistas são responsáveis, de forma geral, por um papel de grande significância na definição dos preços dos cortes das carnes, em função da sensibilidade e interação com as necessidades e exigências diretas do consumidor (IMEA, 2009a).

Neste contexto, foi possível criar equações preditivas (Tabela 4), por meio de regressão linear simples, com o objetivo de verificar a existência de uma relação funcional entre os preços dos cortes de carne (variável dependente) com os preços da arroba do boi e da vaca (variável independente), ou seja, com base nas altas correlações existentes entre as variáveis analisadas (Tabela 3), buscando encontrar uma equação que mais explicasse a variação no preço de cada corte pela variação do preço pago pelo frigorífico ao pecuarista.

As 12 equações geradas apresentaram coeficientes de determinação acima de 6,1 (Tabela 4). Isto demonstrou que mais de $60 \%$ da variação dos preços dos cortes de carne podem ser explicados pela variação nos preços da arroba do boi e da vaca. Os cortes de carne bovina considerados "carnes de primeira" (Contrafilé, Picanha e Coxão Mole), com exceção dos preços da Picanha em função do preço da arroba da vaca, apresentaram comportamento cúbico. Os cortes de carne bovina consideradas "carnes de segunda" (Acém, Músculo e Cupim), com exceção dos preços do Acém em função do preço da arroba do boi gordo, apresentaram comportamento quadrático.

É conhecido que o brasileiro possui preferência pelos cortes traseiros, ficando os dianteiros sem espaço no mercado interno (ABIEC, 2015), por isso os "cortes de primeira" apresentaram maior oscilação de preço, pois são mais dependentes do poder de compra do consumidor nacional, quando comparados aos "cortes de segunda", que por sua vez são em grande parte destinados ao mercado externo. Em um estudo no sul do Brasil, de 2014 a 2015, revelou que a Picanha foi o corte mais sensível a alteração no preço do Boi gordo, sendo apenas 15 dias o tempo necessário para observar a 
oscilação do preço nas gôndolas (Marques et al., 2015). Para Pascoal et al. (2011), o uso do poder de mercado diferiu de produto para produto, o que indica que os varejistas podem adotar estratégias de preços baseadas nas características da demanda dos produtos.

Tabela 4. Equações de regressão linear simples do preço em $\mathrm{kg}$ dos cortes de carne bovina (Contrafilé, Picanha, Coxão Mole, Acém, Músculo e Cupim) em função preço da arroba do Boi gordo [boi] e o da Vaca gorda [vaca] de novembro de 2013 a outubro de 2016

\begin{tabular}{lcc}
\hline \multicolumn{1}{c}{ Variáveis } & Equação & $\mathrm{R}^{2}$ \\
\hline Boi x Contrafilé & $-0,0003275 \times 3+0,1154 \times 2-13,27 \times+520,2$ & 0,77 \\
Vaca x Contrafilé & $-0,0002027 \times 3+0,0672 \times 2-7,187 \times+269,9$ & 0,73 \\
Boi x Picanha & $-0,0002011 \times 3+0,07075 \times 2-7,993 \times+321$ & 0,76 \\
Vaca x Picanha & $0,001243 \times 2-0,02181 \times+19,54$ & 0,80 \\
Boi x Coxão Mole & $-0,0002835 \times 3+0,1008 \times 2-11,74 \times+465,9$ & 0,76 \\
Vaca x Coxão Mole & $-0,0002453 \times 3+0,08226 \times 2-8,993 \times+339$ & 0,76 \\
Boi x Acém & $-0,0002033 \times 3+0,07226 \times 2-8,39 x+329,6$ & 0,66 \\
Vaca x Acém & $0,0006906 \times 2-0,04384 x+8,23$ & 0,61 \\
Boi x Músculo & $0,001202 \times 2-0,193 \times+18,56$ & 0,70 \\
Vaca x Músculo & $0,001429 \times 2-0,2241 \times+19,79$ & 0,69 \\
Boi x Cupim & $0,0006319 \times 2-0,05598 \times+12,87$ & 0,76 \\
Vaca x Cupim & $0,0009407 \times 2-0,1134 x+16,04$ & 0,76 \\
Fonte: Resultados originais da pesquisa &
\end{tabular}

Assim, a regressão permitiu construir um modelo matemático que representou dois atributos ( $x$ e y), e utilizou estas equações para predizer o valor dos cortes para um dado valor pago à arroba do boi ou da vaca dentro da amplitude dos dados avaliados, ou seja, realizou previsões sobre o comportamento futuro dos cortes estudados diante do fenômeno observado na realidade. Neste caso extrapolou-se para o futuro as relações de causa-efeito, observadas no passado, entre as variáveis.

Contudo, por mais que as equações geradas puderam ser utilizadas para predizer os preços dos cortes avaliados, em função dos preços da arroba do boi gordo e da vaca gorda, ratificou que a composição dos preços envolve uma gama de outros fatores, como mencionados anteriormente. A oferta e demanda, impostos, exportações e consumo de carnes alternativas, foram entre os principais fatores que podem, em função do momento econômico, interferir de maneira decisiva no preço da carne.

O aumento da complexidade da cadeia da carne, com a crescente exigência dos consumidores e o processo de diferenciação, transformaram a commodity carne em cortes de carne com marca e maior valor agregado (Pascoal et al., 2011). Diante destes 
cenários, a cadeia precisa melhorar sua organização negocial, uma vez que a estruturação é prejudicada pela falta de confiança entre os elos e o crescente poder do varejo, que em função da grande concentração, tem sido o grande beneficiado com essa desorganização (Ferreira e Padula, 2002).

\section{Conclusão}

O comportamento dos preços do $\mathrm{kg}$ dos cortes da carne bovina apresenta-se variável ao longo do tempo, sendo este afetados diretamente pelo preço da arroba do boi gordo e da vaca gorda. A arroba destes animais tem seus preços influenciados principalmente pela oferta de matrizes para o abate, pelo clima que controla a oferta de alimento e, por fatores econômicos que afetam os diferentes elos da cadeia da carne.

Os preços do kg dos cortes de carne bovina (Contrafilé, Picanha, Coxão Mole, Acém, Músculo e Cupim) estão, forte e positivamente, relacionados com os preços da arroba do boi gordo e da vaca gorda, permitindo sua estimativa a partir de modelos empíricos.

\section{Referências}

Abrita, M.B.; Santos, A.S.; Gonçalves, G. 2014. Análise empírica dos determinantes do preço da arroba do Boi gordo no período de 1995 até 2012: Uma abordagem com base em um modelo VAR. In: XIII Encontro de Ensino, Pesquisa e Extensão ENEPEX. Disponível em: <https://anaisonline.uems.br/index.php/enic/user/setLocale/NEW_LOCALE\%3Fsource \%3D\%252Findex.php\%252Fenic\%252Farticle\%252Fview\%252F2250\%252F0+\&cd=1 \&hl=pt-BR\&ct=clnk\&gl=br>. Acesso em: 10 nov. 2016.

Aguiar, D.R.D. 1993. A questão da transmissão de preços agrícolas. Revista de economia e sociologia rural 31: 291-308.

Arbage, A.P. 2000. Economia rural: conceitos básicos e aplicações. Editora Argos, Chapecó, Santa Catarina, Brasil.

Arruda, Z.J. 2002. Modelo de análise econômica da produção de gado de corte. In: Barbosa, P.F. Assis, A.G. Costa, M.A.B. Modelagem e simulação de sistemas de produção animal. Embrapa Pecuária Sudeste, São Carlos, São Paulo, Brasil.

Associação Brasileira das Indústrias Exportadoras de Carnes [ABIEC]. 2015. Carne brasileira abastece fast food global. Disponível em: <http://www.abiec.com.br/news/texto.asp?idN=1202\&id=23756\#.WloVVIUrLIU>. Acesso em: 26 jan. 2017.

Associação Brasileira das Indústrias Exportadoras de Carnes [ABIEC]. 2016. Perfil da Pecuária no Brasil - Relatório Anual 2016. Disponível em:

<http://abiec.siteoficial.ws/images/upload/sumario-pt-010217.pdf>.

Acesso em: 03 abr. 2017. 
Boechat, A.M.F. 2014. Análise do comportamento dos preços do boi gordo e do boi magro entre 200 e 2012. Revista de Economia e Agronegócio 11: 419-438.

Carvalho, T.B.; Zen, S. 2010. Cadeia de pecuária de corte: perspectivas de produção e consumo no Brasil. In: 48 Congresso SOBER: Sociedade Brasileira de Economia, Administração e Sociologia Rural. Disponível em:

http://www.sober.org.br/palestra/15/166.pdf. Acesso em: 03 nov. 2016.

Corrêa, A.S. 1988. Produção e comércio de carne bovina. Editora EMBRAPA/CNPGC, Campo Grande, Mato Grosso do Sul, Brasil.

Dancey, C.; Reidy, J. 2006. Estatística Sem Matemática para Psicologia: Usando SPSS para Windows. Artmed, Porto Alegre, Rio Grande do Sul, Brasil.

De Paula, A.C.L.; Soares, B.M.; Bonfim, M.D. 2011. A variação do custo da cesta básica para o consumidor. Revista de Iniciação Científica da Libertas 1: 56-71.

Departamento Intersindical de Estatística e Estudos Socioeconômicos [DIEESE]. 2016. Pesquisa nacional da cesta básica de alimentos. Disponível em: <http://sindadosba.org.br/wp-content/uploads/2016/07/Cesta-B\%C3\%A1sica-Junho16.pdf>. Acesso em: 20 abr. 2017.

Ferreira, G.C.; Padula, A.D. 2002. Gerenciamento de cadeia de suprimentos: Nova formas de organização na cadeia da carne bovina do Rio Grande do Sul. Revista Administração Contemporânea 6: 167-184.

Instituto Brasileiro de Geografia e Estatística [IBGE]. 2012. POF (Pesquisa de Orçamentos Familiares). Disponível em: <http://www.ibge.gov.br>. Acesso em: 10 nov. 2016.

Instituto Brasileiro de Geografia e Estatística [IBGE]. 2016. Rebanho efetivo bovino. Disponível em:

<http://saladeimprensa.ibge.gov.br/noticias.html?view=noticia\&id=1\&idnoticia=3268\&b usca=1\&t=ppm-rebanho-bovino-alcanca-marca-recorde-215-2-milhoes-cabecasproducao-leite>. Acesso em: 04 nov. 2016.

Instituto Mato-Grossense de Economia Agropecuária [IMEA]. 2009a. Margem de comercialização da carne bovina nos diferentes elos da cadeia. Disponível em: <http://www.imea.com.br/upload/pdf/arquivos/2009_11_margem_comercializacao.pdf> . Acesso em: 02 nov. 2016.

Instituto Mato-Grossense de Economia Agropecuária [IMEA]. 2009b. Estatística Preços. Disponível em: <http://www.imea.com.br/site/precos.php>. Acesso em: 28 out. 2016.

Lazzarini Neto, S.; Nehmi Filho, V.A. 1997. Pecuária de corte moderna: produtividade e lucro. p. 71. In: Lopes, M.A. Informática aplicada à bovinocultura. FUNEP, Jaboticabal, São Paulo, Brasil.

Marques, C.S.S.; Barcellos, J.O.J.; Dias, E.A.; Pereira, G.R.; Gonzalez, F.A.L.; Lopes, J.F.; Fornari, G.B.; Bitello, M.F.O.; Marques, T.R. 2015. Preço da carne bovina no varejo em Porto Alegre, RS. 2015. In: Pereira, G.R.; Oliveira, T.E.; Barcellos, J.O.J. II Simpósio Internacional Sobre Sistemas de Produção de Bovinos de Corte. Porto 
Alegre, RS, Brasil. Disponível em:

$<$ http://www.ufrgs.br/nespro/arquivos/anais_jornadas/anais_x_jornada_nespro_2015.p df>. Acesso em: 10 nov. 2016.

Martins, S.S.; Pinatti, E.; Igreja, A.C.M. 2009. Cadeia produtiva da pecuária de Corte: Ciclos pecuários e indicadores de lucro bruto. In: Congresso da Sociedade Brasileira de Economia, Administração e Sociologia Rural. Porto Alegre. CD-ROM.

Montoya, M.A.; Parre, J.L. 2000. O agronegócio brasileiro no final do século XX: Estrutura produtiva, arquitetura organizacional e tendências. UPF Editora, Passo Fundo, Rio Grande do Sul, Brasil.

Moore, D.S. 2007. The Basic Practice of Statistics. Freeman, New York, New York, United States of America.

Nehmi Filho, V.A. 2007. Novo ciclo de alta da pecuária começa em 2007. p.16-17. In: Anuário da Pecuária Brasileira 2007. Instituto FNP, São Paulo, SP, Brasil.

Pascoal, L.L.; Vaz, F.N.; Vaz, R.Z.; Restle, J.; Pacheco, P.S.; Santos, J.P.A. 2011. Relações comerciais entre produtor, indústria e varejo e as implicações na diferenciação e precificação de carne e produtos bovinos não-carcaça. Revista Brasileira de Zootecnia 40: 82-92.

Pimentel, L. 2011. A história do boi gordo - ciclos pecuários [BEEFPOINT]. Disponível em: <http://www.beefpoint.com.br/cadeia-produtiva/espaco-aberto/a-historia-do-boigordo-ciclos-pecuarios-73696/>. Acesso em: 16 nov. 2016.

Pindyck, R.S.; Rubinfeld, D.L. 1994. Microeconomia. Makron Books, São Paulo, SP, Brasil.

Potter, V.J. 2000. O papel das novas raças na produção de carne. Disponível em: <http://www.crpbz.org.br/PortalUploads/Docs/571.pdf>. Acesso em: 16 jan. 2017.

Raupp, F.M.; Fuganti, E.N. 2014. Gerenciamento de custos na pecuária de corte: Um comparativo entre a engorda de bovinos em pastagem e em confinamento. Custos e Agronegócio on line 10: 282-316.

Sachs, R.C.C.; Margarido, M.A. 2007. Análise da volatilidade dos preços do boi gordo no Estado de São Paulo, uma aplicação dos modelos ARCH/GARCH. In: XLV Congresso da SOBER: Conhecimentos para Agricultura do Futuro. Disponível em: <http://www.sober.org.br/palestra/6/429.pdf>. Acesso em: 11 nov. 2016.

Santana, A.C. 1999. Mudanças recentes nas relações de demanda de carne no Brasil. Revista de Economia e Sociologia Rural 37: 51-76.

Viana, J.G.A.; Souza, R.S.; Silveira, V.C.P.S. 2009. Evolução dos preços históricos da bovinocultura de corte do Rio Grande do Sul: Tendência e comportamento dos preços em nível de produtor e consumidor. Ciência e Agrotecnologia 33: 1109-1117.

Wedekin, I.W. 2009. Entenda como funciona o ciclo pecuário - Palestra Workshop Beef Point de Pecuária de Cria. Disponível em:

$<$ http://www.beefpoint.com.br/cadeiaprodutiva/pecuaria-de-cria/entenda-comofunciona-o-ciclo-pecuario-video-slides-e-artigo- 58166/>. Acesso em: 16 nov. 2016. 